\title{
Do Mediterranean crickets Gryllus bimaculatus De Geer (Orthoptera: Gryllidae) come from the Mediterranean? Largescale phylogeography and regional gene flow
}

\author{
M. Ferreira and J.W.H. Ferguson* \\ Centre for Environmental Studies, Department of Zoology and \\ Entomology, University of Pretoria, Pretoria 0002, South Africa
}

\begin{abstract}
We investigate the degree of between-population genetic differentiation in the Mediterranean field cricket Gryllus bimaculatus, as well as the possible causes of such differentiation. Using cytochrome $b \mathrm{mtDNA}$ sequences, we estimate genetic variation in G. bimaculatus from seven South African and two Mediterranean populations. Within-population genetic variation in Europe (two haplotypes, one unique to a single individual) suggest low effective population size and strong bottlenecks with associated founder effects, probably due to cold winter environments in Europe that limit reproduction to a short part of the summer. The likely cause for this is the daily maxima in winter temperatures that fall below the critical level of $16^{\circ} \mathrm{C}$ (enabling normal calling and courtship behaviour) in Mediterranean Europe, whereas the equivalent temperatures in southern Africa are above this limit and enable reproduction over a large part of the year. European genetic variants were either shared with Africa or closely related to African haplotypes. For survival, European populations are probably dependent on immigration from other areas, including Africa. South African populations have low but measurable gene flow with Europe and show significant between-population genetic differentiation (30 haplotypes). Isolation-by-distance is not sufficient to explain the degree of between-population genetic differences observed, and a large degree of dispersal is also required in order to account for the observed patterns. Differences in morphology and calling behaviour among these populations are underlied by these genetic differences.
\end{abstract}

Keywords: Orthoptera, Mitochondrial DNA, Cytochrome b, Gene flow, Climate

(Accepted 24 December 2008)

\section{Introduction}

Gryllus bimaculatus has a global distribution, spanning Africa, Asia and southern Europe (Ragge, 1972; Harrison \& Bogdanowicz, 1995). It is an eruptive insect with short-lived

*Author for correspondence

Fax: + 27124203210

E-mail: willemferguson@zoology.up.ac.za local peaks in numbers and much lower densities in between. Moreover, G. bimaculatus outbreaks are unpredictable in time and space, due to specific habitat requirements for egg and larval development. Oviposition sites need warmth and moisture (personal observation) and immatures cannot survive cold conditions (van Wyk \& Ferguson, 1995; Ferreira, 2006). Ecological and climatic conditions, therefore, strongly modulate the population numbers of crickets. For instance, changes in weather systems probably led to mass migrations of $G$. bimaculatus from the West 

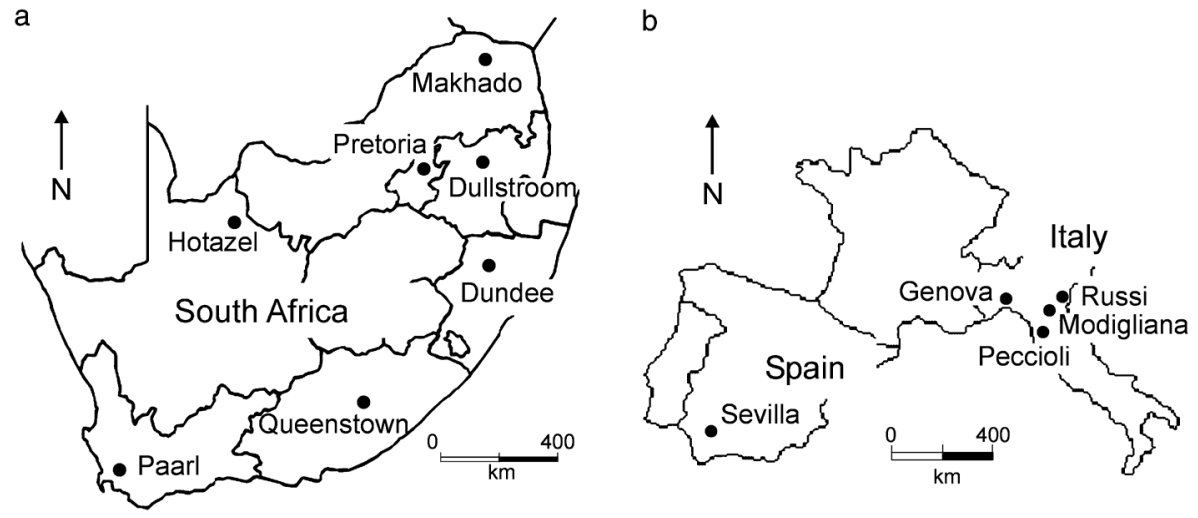

Fig. 1. Map of sampling locations of Gryllus bimaculatus in (a) South Africa and (b) Europe.

African coast towards the Atlantic ocean in 1969 (Ragge, 1972).

Intraspecific phylogeographical patterns have been studied within the context of hybridization between three closely related North American Gryllus species (G. firmus, G. pennsylvanicus and G. ovisopis). Broughton \& Harrison (2003) found little geographical structure and no correlation between genetic distance and geographical proximity for the Ef1 $\alpha$, Cam and Cyt-c nuclear introns in G. firmus and G. pennsylvanicus. However, they argue that ancestral polymorphisms have persisted through the divergence of G. firmus, G. pennsylvanicus and G. ovisopis and that this rather than gene flow explains the observed deep coalescence of the nuclear loci. On the other hand, the COI-COII mtDNA gene revealed substantial intraspecific genetic structure in G. firmus and G. pennsylvanicus with both species having a north-south split (Willet et al., 1997). These authors suggested that, although contemporary gene flow accounted for intraspecific patterns of allele frequency variation, the distinctness of mtDNA haplotypes between northern and southern clades argued against the gene flow hypothesis. Phylogeographical analyses can give fundamental insights to understanding geographical variation in morphological as well as behavioural traits across taxa. For instance, after clinal variation had been observed in the advertisement call of the túngara frog, Physalaemus pustulosus, genetic analyses by Ryan et al. (1996) suggested that call similarities between populations located close to each other were due to gene flow or through a common ancestor. Ferreira \& Ferguson (2002, unpublished data) found significant geographical variation in the calling song, as well as morphological traits, of $G$. bimaculatus. In order to glean a better understanding of the underlying mechanisms contributing to this geographical variation, it is necessary to quantify the degree of gene flow, as well as possible historical geographical differentiation, for several populations of G. bimaculatus.

In this study, we aim to determine geographical variation in cytochrome $b$ (cyt $b$ ) mtDNA sequences in G. bimaculatus from South Africa, Spain and Italy, to use several techniques to estimate gene flow and migration rates between different geographical areas in South Africa and Europe and, lastly, to infer historical biogeographical processes for explaining the observed genetic variation.

\section{Materials and methods}

Sampling localities and genomic DNA extraction

Male crickets were sampled from 2000 to 2003 at seven localities in South Africa (fig. 1a; Dullstroom: $25^{\circ} 5^{\prime} \mathrm{S}$, $30^{\circ} 00^{\prime} \mathrm{E}$; Dundee: $28^{\circ} 15^{\prime} \mathrm{S}, \quad 30^{\circ} 23^{\prime} \mathrm{E}$; Hotazel: $27^{\circ} 14^{\prime} \mathrm{S}$, $22^{\circ} 57^{\prime} \mathrm{E}$; Makhado: $23^{\circ} 05^{\prime} \mathrm{S}, 2^{\circ} 59^{\prime} \mathrm{E}$; Paarl: $33^{\circ} 14^{\prime} \mathrm{S}$, $18^{\circ} 56^{\prime} \mathrm{E}$; Pretoria: $25^{\circ} 41^{\prime} \mathrm{S}, 28^{\circ} 13^{\prime} \mathrm{E}$; Queenstown: $31^{\circ} 52^{\prime} \mathrm{S}$, $26^{\circ} 52^{\prime} \mathrm{E}$ ) and two regions in Europe (fig. 1b; Italy, Spain Cota Donãna). The Italian sample comprised four males from Genova $\left(44^{\circ} 24^{\prime} \mathrm{N}, 8^{\circ} 54^{\prime} \mathrm{E}\right)$, two from Modigliana $\left(44^{\circ} 8^{\prime} \mathrm{N}\right.$, $\left.11^{\circ} 46^{\prime} \mathrm{E}\right)$ and one each from Peccioli $\left(43^{\circ} 32^{\prime} \mathrm{N}, 10^{\circ} 43^{\prime} \mathrm{E}\right)$ and Russi $\left(44^{\circ} 22^{\prime} \mathrm{N}, 12^{\circ} 1^{\prime} \mathrm{E}\right)$. Due to few animals from each locality in Italy, they were treated as a single Italian sample. The Spanish sample comprised 20 males from Sevilla $\left(37^{\circ} 24^{\prime} \mathrm{N}, 6^{\circ} 59^{\prime} \mathrm{W}\right)$. In total, 133 individuals from South Africa and 28 individuals from Europe were sequenced. Crickets were stored at $-70^{\circ} \mathrm{C}$ until DNA was extracted from tarsi using 5\% Chelex $100^{\circledR}$ (Walsh et al., 1991) and stored at $-20^{\circ} \mathrm{C}$.

\section{PCR amplification and sequencing}

Species-specific forward 197F: 5'GTTGGACGTGGAATATATTA $3^{\prime}$ and reverse 925R: 5'GCACCGATTCAAGTTAATAA3' primers were designed to amplify a $728 \mathrm{bp}$ fragment of the cyt $b$ gene. Polymerase chain reaction (PCR) was performed using a GeneAmp system 2400 thermal cycler (Perkin Elmer Applied Biosystems) using a total reaction volume of $50 \mu \mathrm{l}$. Concentrations and volumes of the reagents for each amplification reaction were as follows: $1 \mu \mathrm{l}$ of DNA template, $2.5 \mu \mathrm{l}$ of each primer $\left(10 \mathrm{pmol} \mu \mathrm{l}^{-1}\right)$, $4 \mu \mathrm{l}$ of dNTPs $(2.5 \mathrm{mM}), 5 \mu \mathrm{l}$ of $10 \times$ buffer, $1 \mu \mathrm{l}$ of Taq DNA polymerase ( $1 \mathrm{U}^{-1} \mathrm{l}^{-1}$; Biotools) and $34 \mu \mathrm{l}$ of $\mathrm{ddH}_{2} 0$. Thermal cycling parameters were as follows: 20 s preheat at $96^{\circ} \mathrm{C}$, one cycle of initial denaturation at $95^{\circ} \mathrm{C}$ for $20 \mathrm{~s}$, annealing at $50^{\circ} \mathrm{C}$ for $25 \mathrm{~s}$, extension at $72^{\circ} \mathrm{C}$ for $60 \mathrm{~s}$ and 39 cycles of denaturation at $95^{\circ} \mathrm{C}$ for $15 \mathrm{~s}$, annealing at $49.5^{\circ} \mathrm{C}$ for $15 \mathrm{~s}$, extension at $72^{\circ} \mathrm{C}$ for $50 \mathrm{~s}$ and one cycle of final extension at $72^{\circ} \mathrm{C}$ for $60 \mathrm{~s}$ and held at $5^{\circ} \mathrm{C}$. Negative controls containing no DNA template were included in each set of amplification reactions. After checking PCR products on a $1.5 \%$ agarose gel, stained with ethidium bromide, they were purified using the High Pure PCR Product Purification kit (Roche 
Diagnostics Corporation) following the manufacturer's specifications.

All PCR products were sequenced in both directions. Purified DNA was cycle sequenced using a GeneAmp thermal cycler utilising $10 \mu \mathrm{l}$ reactions, each of which comprised $2 \mu \mathrm{l}$ of the Big Dye Terminator cycle Sequencing Ready Reaction kit (fourfold diluted; Perkin Elmer), $1 \mu \mathrm{l}$ of $5 \times$ sequencing buffer, $1 \mu \mathrm{l}$ of primer $\left(3.2 \mathrm{pmol} \mu \mathrm{l}^{-1}\right), 2-6 \mu \mathrm{l}$ of DNA template and the remainder comprising $\mathrm{ddH}_{2} \mathrm{O}$. The amount of DNA template and $\mathrm{ddH}_{2} \mathrm{O}$ used were determined by the PCR product yield. Conditions for thermal cycling were: 25 cycles of denaturation at $96^{\circ} \mathrm{C}$ for $10 \mathrm{~s}$, annealing at $54^{\circ} \mathrm{C}$ for $5 \mathrm{~s}$ and extension at $60^{\circ} \mathrm{C}$ for $4 \mathrm{~min}$ and held at $4^{\circ} \mathrm{C}$. Sequencing was performed on ABI Prism 377 and 3100 DNA Sequencers (Perkin Elmer). Sequence chromatograms were visualized using Chromas v1.43 (McCarthy, 1996) and aligned and edited in Dapsa v4.9 (Harley, 2000).

\section{Testing for mitochondrial pseudogenes}

Nuclear mtDNA pseudogenes have been found in several orthopteran species, namely Schistocerca gregaria (Zhang \& Hewitt, 1996), and in ten species from the families Acrididae, Podisminae, Calliptaminae, Cyrtacanthacridinae and Gomphocerinae (Bensasson et al., 2000). Consequently, all cyt $b$ sequences in this study were checked for characteristics consistent with mtDNA pseudogenes (Arctander, 1995), and each chromatogram was checked for double peaks at each nucleotide. Pure mtDNA of five individuals (two from Pretoria, one from a laboratory-reared colony, two from Sevilla) was extracted using a Cesium Chloride gradient (CsCl: Lansman et al., 1981). For each individual, the cyt $b$ gene was amplified and sequenced from purified mtDNA as described in the previous paragraph. These were aligned and compared to the genomic DNA extractions (Chelex extraction of Sevilla animals; Roche kit extraction of laboratory-reared and Pretoria animals, following manufacturer's specifications).

In order to verify that the mtDNA was free of nuclear DNA, the extracted pure mtDNA of each male was amplified using nuclear ribosomal primers $\left(18_{\mathrm{s}} \mathrm{F}\right.$ and $\left.5.8_{\mathrm{s}} \mathrm{R}\right)$, yielding a $962 \mathrm{bp}$ region of the ITS gene (Ji et al., 2003). It was assumed that a $\mathrm{CsCl}$ extraction of mtDNA contained no nuclear DNA if there was no PCR product using the ribosomal primers. Application of these primers to amplify genomic extractions (Roche kit) from these crickets yielded clear PCR products. PCR was performed using a GeneAmp thermal cycler with a total reaction volume of $50 \mu \mathrm{l}$. Concentrations and volumes of the reagents for each amplification reaction were: $1 \mu \mathrm{l}$ of DNA template, $2.5 \mu \mathrm{l}$ of each primer $\left(10 \mathrm{pmol}_{\mu \mathrm{l}}^{-1}\right), 4 \mu \mathrm{l}$ of dNTPs $(2.5 \mathrm{mM}), 5 \mu \mathrm{l}$ of $10 \times$ buffer, $1 \mu \mathrm{l}$ of Taq DNA polymerase $\left(1 \mathrm{U} \mu \mathrm{l}^{-1}\right.$; Biotools) and $34 \mu \mathrm{l}$ of $\mathrm{ddH}_{2} 0$. Thermal cycling parameters were as follows: $4 \mathrm{~min}$ preheat at $94^{\circ} \mathrm{C}, 35$ cycles of denaturation at $95^{\circ} \mathrm{C}$ for $20 \mathrm{~s}$, annealing at $50^{\circ} \mathrm{C}$ for $40 \mathrm{~s}$, extension at $72^{\circ} \mathrm{C}$ for $90 \mathrm{~s}$ and one cycle of final extension at $72^{\circ} \mathrm{C}$ for $20 \mathrm{~s}$ and held at $4^{\circ} \mathrm{C}$. One positive control (genomic DNA template using ITS primers) and one negative control (no DNA template using ITS primers) were included with each set of amplification reactions. PCR products were checked on a $1.5 \%$ agarose gel, stained with ethidium bromide.

\section{Genetic differentiation and gene flow}

Analyses were performed in two ways, the first comprising both the South African and Mediterranean populations (African-Mediterranean data set) and the second comprising only South African populations (South African data set). Modeltest v3.06 (Posada \& Crandall, 1998) was used to determine the appropriate substitution model given the observed data. Haplotype diversity $(h)$ and nucleotide diversity $(\pi)$ were calculated for each population using Arlequin v2.000 (Schneider et al., 2000).

A $\chi^{2}$ contingency test was performed to determine significant geographical associations using 100,000 randomized permutations (Roff \& Bentzen, 1989). In addition to this, a Mantel test (Mantel, 1967) was performed to test for an association between the genetic distances obtained in Arlequin and the geographical distances between populations. Ten thousand randomized permutations were performed using Mantel v2.0 (Liedloff, 1999).

An analysis of molecular variance (AMOVA: Excoffier et al., 1992), using Arlequin, was performed to evaluate the degree of within-population and among-population genetic differentiation for both data sets using pairwise $F_{\mathrm{ST}}$ statistics, allowing estimation of the number of migrants between populations per generation. In addition, Migrate v1.7.6.1 (Beerli, 2004) was used to calculate Bayesian estimates for migration rates among populations under a symmetrical migration model. The analysis on the African-Mediterranean data set was inconclusive, and the analysis was, therefore, performed only on the South African data set. One hundred short chains with 500 sampled genealogies each and three long chains with 5000 sampled genealogies each were run. One of every 20 reconstructed genealogies was sampled; therefore, the total number of reconstructed genealogies was $10^{4}$ for each short chain and $10^{5}$ for each long chain. Heating was set to adaptive, with temperature settings of 1.0, 1.2, 1.5 and 3.0.

TCS v1.13 (Clement et al., 2000) was used to estimate a single mutation haplotype network (probability >0.95) from DNA sequences for both data sets as described by Templeton et al. (1992). Identical sequences were collapsed to single haplotypes and haplotype frequencies were calculated for estimating haplotype outgroup probabilities, which correlate with haplotype age (Donnelly \& Tavaré, 1986; Castelloe \& Templeton, 1994). The haplotype network was converted into a nested series of clades using the rules in Templeton \& Sing (1993), after which a nested clade analysis was performed, using Geodis v2.0 (Posada et al., 2000) and the inference key of Templeton (2004). Again, the analysis performed on the African-European data set was inconclusive due to the large non-sampled area between South Africa and Europe. The Mediterranean data were, therefore excluded from this analysis. One thousand random permutations were performed to obtain statistical inferences at the $5 \%$ level.

\section{Results \\ Nuclear pseudogenes}

Firstly, all cyt $b$ sequences translated successfully into proteins and no stop codons were encountered. Secondly, although isolated incidences of double peaks were encountered in some of the sequences, they did not occur consistently at the same positions of both forward and 


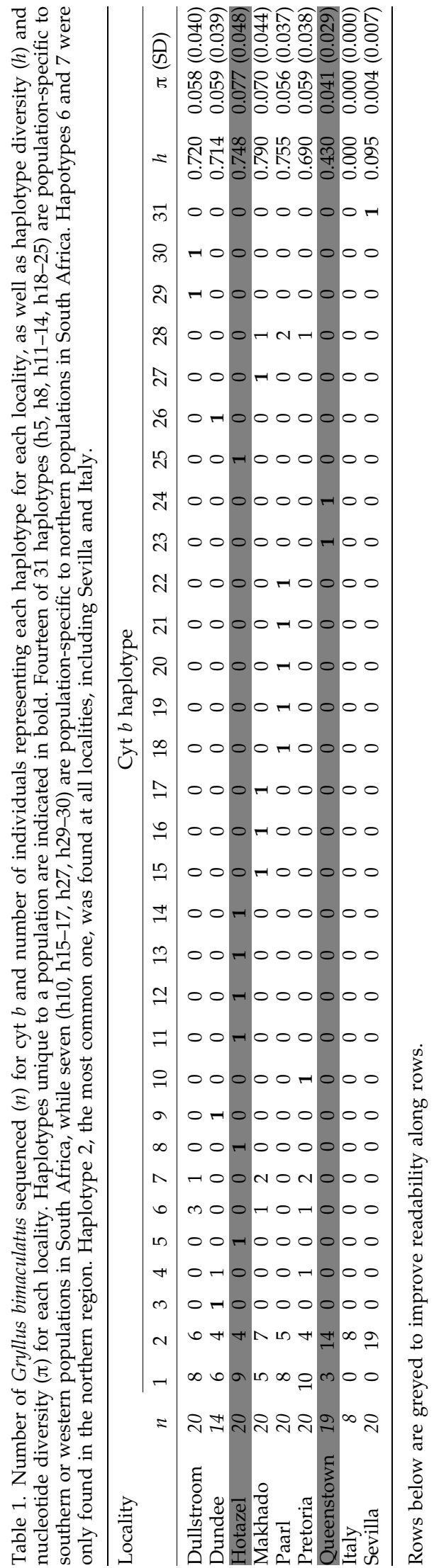

reverse sequences, and it is suspected that these peaks were artifacts of the sequencing reaction itself. E.g. Isolate Q6 (Genbank accession number EF093650) only had double peaks in the forward sequence (positions 48, 135, 158), while Isolate Q2 (Genbank accession number EF093646) had double peaks in both forward (positions 8, 111, 128, 188, 326) and reverse (position 275, 305, 507, 563) sequences. Thirdly, when the sequences obtained through $\mathrm{CsCl}$ extractions were compared with those from genomic DNA extractions, not a single inconsistency was found between the two sources of DNA. Fourthly, a large degree of sequence variation was not observed, comparable to those found in the nuclear copies of mitochondrial genes in orthoptera (Zhang \& Hewitt, 1996). The ITS primers yielded a good PCR product when using genomic DNA extractions. On the other hand, the $\mathrm{CsCl}$ extractions did not allow amplification of the ITS gene in any of the five individuals tested, suggesting that the purified mtDNA extraction was free of nuclear DNA. This indicates that the cyt $b$ DNA sequenced was of mitochondrial origin and did not constitute nuclear pseudogenes.

\section{MtDNA haplotype variation}

It was decided to use only $575 \mathrm{bp}$ of the targeted $728 \mathrm{bp}$ region of the cyt $b$ gene in the analyses. This region could not be successfully sequenced for all individuals. However, for the large majority of individuals that could be successfully sequenced, these flanking regions did not reveal any additional haplotypes. All sequences were deposited in GenBank (Accession Nos EF093592-EF093752). The 161 crickets from South Africa and Europe yielded 31 haplotypes (table 1) defined by 35 polymorphic nucleotide sites. Genbank accession numbers for the haplotypes are as follows: h1: EF093629, h2: EF093640, h3: EF093602, h4: EF093643, h5: EF093620, h6: EF093632, h7: EF093645, h8: EF093608, h9: EF093592, h10: EF093638, h11: EF093607, h12: EF093618, h13: EF093621, h14: EF093622, h15: EF093672, h16: EF093702, h17: EF093678, h18: EF093687, h19: EF093689, h20: EF093704, h21: EF093692, h22: EF093695, h23: EF093650, h24: EF093652, h25: EF093616, h26: EF093605, h27: EF093681, h28: EF093634, h29: EF093737, h30: EF093748, h31: EF093710. Six haplotypes were found at two or more localities (h1, h2, h4, h6, h7 and h28; table 1). The most common haplotype (h2, n=71) was found in all the South African and European populations. The second most common haplotype (h1, $n=49$ ) was found only in South Africa. Only two haplotypes were found in Europe (h2 and h31; table 1), the latter from a single cricket from Spain while h2 was also common in South Africa. Modeltest suggested that the most appropriate approach for estimating within-population genetic diversity for both data sets was the Tamura-Nei ( TrN) model (Tamura \& Nei, 1993). The estimated transition/transversion ratio was 11.048 for the combined African-Mediterranean data set and 10.501 for the South African data set.

\section{Within-population genetic differentiation}

Haplotype diversity $(\mathrm{h})$ and nucleotide diversity $(\pi)$ differed largely among populations, with the lowest haplotype and nucleotide diversity values observed in the Mediterranean populations. Nucleotide diversity in the total data set was $6.09 \%$. For South Africa, the Hotazel population had the highest nucleotide diversity and Queenstown the lowest, 
Table 2. Estimated migration rates per generation between southern African populations of Gryllus bimaculatus derived from a MCMC maximum likelihood estimation (Beerli, 2004).

\begin{tabular}{|c|c|c|c|c|c|c|c|c|}
\hline \multirow[t]{2}{*}{ Population } & \multirow[t]{2}{*}{$n$} & \multirow{2}{*}{$\begin{array}{c}\text { Effective population size } \\
(4 \mathrm{Ne} \mu)\end{array}$} & \multicolumn{6}{|c|}{ Migration rate (4Nm) } \\
\hline & & & Dullstroom & Dundee & Hotazel & Makhado & Paarl & Pretoria \\
\hline Dullstroom & 20 & 0.01141 & & & & & & \\
\hline Hotazel & 20 & 0.00141 & 38.43680 & 0.02190 & & & & \\
\hline Makhado & 20 & 0.00037 & 61.97450 & 16.54800 & 0.01250 & & & \\
\hline Paarl & 20 & 0.00088 & 86.76480 & 0.00630 & 22.29770 & 0.21390 & & \\
\hline Pretoria & 20 & 0.00170 & 58.82090 & 0.00017 & 0.02180 & 0.17910 & 58.21410 & \\
\hline
\end{tabular}

Migration was assumed to be symmetrical; $n$, the number of individuals sequenced at each locality.

Table 3. Population pairwise $F_{\mathrm{ST}}$ statistics (Tamura-Nei distance parameter) for the South African and Mediterranean populations of Gryllus bimaculatus, derived from AMOVA (lower diagonal area of the table). Asterisks indicate significant $F_{\mathrm{ST}}$ statistics $(P<0.05 *$, $P<0.01^{* *}$ and $\left.P<0.001^{* * *}\right)$, while negative values indicate a larger degree of within-population variation than between-population genetic differences.

\begin{tabular}{|c|c|c|c|c|c|c|c|c|c|}
\hline \multirow[t]{2}{*}{ Population } & \multicolumn{9}{|c|}{ Population pairwise $\mathrm{F}_{S T}$ 's and number of migrants per generation } \\
\hline & Dundee & Dullstroom & Hotazel & Italy & Makhado & Paarl & Pretoria & Queenstown & Sevilla \\
\hline Dundee & & 749.09 & Inf & 0.51 & 22.13 & Inf & 48.02 & 1.03 & 0.33 \\
\hline Hotazel & -0.015 & -0.016 & & 0.70 & 51.41 & Inf & Inf & 1.27 & 0.49 \\
\hline Italy & $0.493^{* * *}$ & $0.443^{* * *}$ & $0.416^{* * *}$ & & 1.21 & 0.44 & 0.55 & 3.42 & Inf \\
\hline Makhado & -0.022 & -0.038 & 0.010 & $0.291^{* * *}$ & & Inf & 52.02 & 3.15 & 0.84 \\
\hline Paarl & -0.092 & -0.054 & -0.181 & $0.530^{* * *}$ & -0.156 & & Inf & 1.40 & 0.31 \\
\hline Sevilla & $0.601^{* * *}$ & $0.530 * * *$ & $0.503^{* * *}$ & 0.000 & $0.373^{* * *}$ & $0.613^{* * *}$ & $0.559^{* * *}$ & $0.18^{*}$ & \\
\hline
\end{tabular}

The upper diagonal area of the table shows the estimated number of migrants per generation ( $2 \mathrm{Nm})$. 'Inf' indicates an infinite number of migrants per generation among populations.

indicating a large degree of within-population differentiation in the Hotazel population and a small degree of withinpopulation differentiation in the Queenstown population (table 1). The low nucleotide diversity in the Queenstown population is also reflected in its haplotype diversity. Six of the seven South African populations had haplotype diversities larger than 0.69 , indicative of a high degree of overall within-population genetic diversity. The low nucleotide diversity of the Mediterranean populations was also reflected in the haplotype diversities and indicated a small degree of within-population genetic differentiation. The relative effective population sizes (table 2) reflected the degree of within-population differentiation (based on nucleotide diversity; table 1) in the South African populations. While the Queenstown population had the smallest effective population size and the lowest nucleotide diversity, the Dullstroom population had the largest effective population size, and its nucleotide diversity was similar to three other well-established populations. The number of individuals sampled from the Mediterranean $(n=28)$ represents a smaller sample size than we obtained in South Africa. However, except for one individual from Spain with a unique haplotype, all Mediterranean crickets shared the same cyt $b$ haplotype (table 1) that was also the most common in southern Africa.

\section{Between-population genetic differentiation}

There was significant between-population genetic differentiation among the sampled populations. For the
African-Mediterranean data set, AMOVA indicated that $80.51 \%$ of the genetic variation occurred within populations and $19.49 \%$ among populations, revealing significant between-population genetic differentiation $\left(F_{\mathrm{ST}}=0.195\right.$, $P<0.001)$. For the South African data set, AMOVA also revealed significant between-population genetic differentiation $\left(F_{\mathrm{ST}}=0.049, P<0.05\right)$ and indicated that $5 \%$ of the genetic variation occurred among populations and $95 \%$ of the variation occurred within populations. As expected, the estimated number of migrants per generation was higher between the South African populations than between the South African and Mediterranean populations (table 3). The results of the Roff-Bentzen test supported the AMOVA. There was significant geographical differentiation in the African-Mediterranean data set (observed $\chi^{2}=271.53$, $P \ll 0.05, n=161)$ as well as within the South African data set (observed $\chi^{2}=190.19, P<0.05, n=133$ ). This reflects the small number of haplotypes in the Mediterranean compared with South Africa. Two common haplotypes were restricted to the northern populations (Dullstroom, Makhado, Pretoria). Seven haplotypes were restricted to the Hotazel population and five haplotypes to the Paarl population. This represents a significant north-south degree of differentiation (table 1), reflected in the above statistics. Two possible migration routes were suggested within South Africa, based on the migration estimates of migrate (maximum log likelihood $=$ 3.585; table 2). Firstly, large degrees of gene flow occurred among the populations in the northeastern region of South Africa (Dullstroom, Dundee, Makhado, Pretoria). Secondly, migration took place among the Hotazel, Paarl 
a

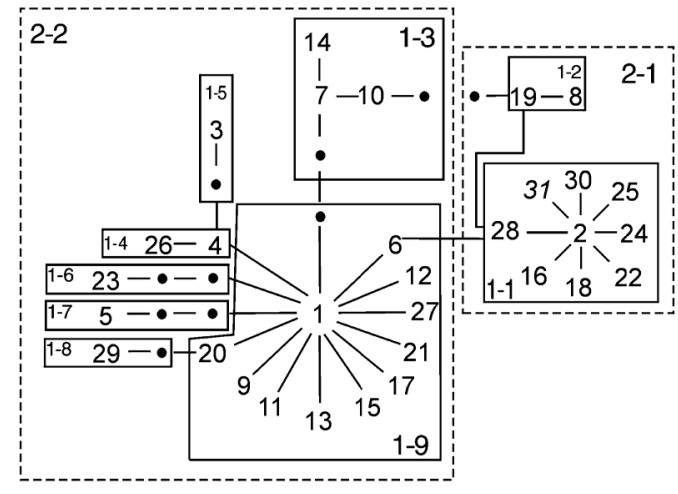

b

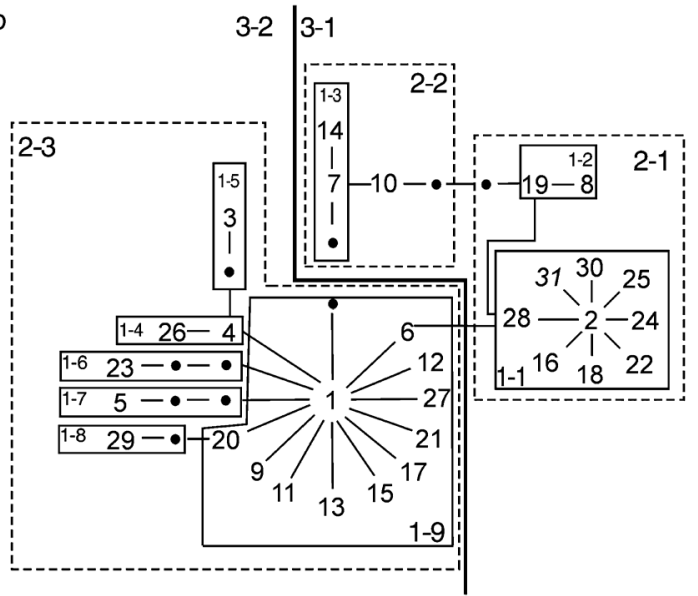

Fig. 2. Haplotype network and associated nested design for cyt $b$ haplotypes from seven South African populations of Gryllus bimaculatus based on the statistical parsimony of Templeton \& Sing (1993). Haplotypes from Italy and Spain were excluded form the NCA due to large non-sampled areas between South Africa and Europe. For descriptive purposes, the unique haplotype (h31) from the Spanish population is indicated in italics in clade 1-1. Separate analyses performed to accommodate an internal loop in the haplotype network resulted in a (a) two-step cladogram and a (b) three-step cladogram. Hypothetical haplotypes are indicated by a black dot and are separated by increments of single mutational steps. One-step, two-step and three-step clades are indicated respectively by thin line, dotted line and thick line boxes labeled by hyphened numbers. Haplotype ID numbers in table 1 are used in this figure.

and Queenstown populations situated in the southwestern region of South Africa.

\section{Isolation by distance}

No significant isolation-by-distance effect was observed among the South African populations (Mantel test: $g=0.306$, $\mathrm{r}=0.096, P>0.05, n=133)$, suggesting that, although there was significant between-population genetic differentiation, simple isolation by geographic distance was not the major determinant of these genetic differences. A significant isolation-by-distance effect was observed for the AfricanMediterranean data set (Mantel test: $\mathrm{g}=3.607, \mathrm{r}=0.776$, $P<0.05, n=161)$, suggesting that, on a broader scale, isolation by geographic distance was a determinant of betweencontinent genetic differentiation. However, this latter result is possibly an artifact due to the large unsampled distance between the Mediterranean and southern Africa.

\section{Haplotype network analysis}

The haplotypes from crickets in Spain and Italy nested totally within the haplotype network of the South African crickets (fig. 2). Except for a single individual from Spain containing a unique haplotype, all Mediterranean crickets had a haplotype that is common in South Africa (table 1). However, since inclusion of the Mediterranean data did not result in robust conclusions due to a large unsampled area between South Africa and Europe, only the results for the South African data set is discussed here. The haplotype network included a loop. Consequently, two alternative cladograms were constructed that comprised two two-step clades (two-step cladogram; fig. 2a) and two three-step clades (three-step cladogram; fig. 2b), respectively, depending on where the loop was broken. The oldest interior clade (1-9) and the younger tip clades comprised haplotypes from all the South African populations. However, with the exception of clade 1-8, the geographical representation of the tip clades were restricted to certain regions of the country (clades 1-4 and 1-5 represented the northeastern region), suggesting restricted gene flow between areas of the country.

The two-step cladogram (fig. 2a) comprised nine onestep clades and two two-step clades. Clade 2-1 mostly comprised haplotypes from the southern region of South Africa (Hotazel, Paarl, Queenstown), while clade 2-2 mostly comprised haplotypes from the northeastern region (Dullstroom, Dundee, Makhado, Pretoria).

The three-step cladogram (fig. 2b) differed from the twostep cladogram by having three two-step clades and two three-step clades. Most of the populations from the southern region of South Africa were nested within clade 3-1 and the populations from the northeastern region nested within clade 3-2.

The nested clade analysis showed significant differences for within-clade $(D c)$ and nested clade (Dn) distances (table 1) at the top level for both cladograms (two-step clade, fig. 2a; $\chi^{2}=16.23, \quad P<0.01$; three-step clade, fig. $2 \mathrm{~b}: \chi^{2}=12.21$, $P<0.05)$. Within both these clades, restricted gene flow with isolation by distance was the most likely explanation for the pattern.

\section{Discussion}

Purified mtDNA sequences of five individual crickets matched those of their genomic mtDNA extractions, indicating that the results in this study reflected variation at the mitochondrial cyt $b$ gene of G. bimaculatus and that no nuclear products were amplified as has been found in a number of Orthoptera species (Zhang \& Hewitt, 1996; Bensasson et al., 2000).

\section{Genetic variation in Mediterranean crickets}

A combined genetic analysis of the Mediterranean and South African populations is complicated by a large nonsampled area between these two areas. For this reason, 
several of the analyses were performed only for the South African populations. For the Mediterranean crickets, the sample size of 28 individuals is not very large, and the reduced haplotype variation could be an artifact of sample size. However, the Roff-Bentzen test indicates that, using our collective dataset of haplotypes as a source, the probability of drawing a random sample of sequences with haplotype composition similar to that observed in the Mediterranean is negligible. In addition, all South African populations with similar sample size as that of Sevilla had at least four haplotypes (table 1). The low haplotype number in the Mediterranean is unlikely to be due to inbred maternal lines affecting the mitochondrial haplotype diversity since molecular evidence indicates extensive multiple mating by male crickets (Bretman et al., 2004). The overall characteristics of very low genetic diversity (table 1 ) yet with high betweenpopulation genetic similarity and high estimated rates of gene flow between Mediterranean populations (table 3) can be explained by irruptive outbreaks punctuated by strong within-population bottlenecks. High between-population exchange resulting in founder effects are likely to contribute to these small degrees of genetic diversity among localities but only after existing populations have largely been reduced in size. Winter temperatures in Mediterranean Europe are relatively cold with daily maxima below $15^{\circ} \mathrm{C}$ for localities close to where crickets were collected for this study. Van Wyk \& Ferguson (1995) showed that the communicatory behaviour of $\mathrm{G}$. bimaculatus ceases below an ambient temperature of $16^{\circ} \mathrm{C}$ and that the activity patterns of crickets during the southern African winter is shifted towards diurnal periods with higher temperatures. In addition, Ferreira (2006) showed a $0 \%$ survival rate for cricket larvae reared in captivity at $15^{\circ} \mathrm{C}$ and a $13 \%$ survival at $20^{\circ} \mathrm{C}$. Low winter temperatures in Europe, therefore, probably constitute a strong limiting factor that causes only a small portion of the population to survive through the colder winter months, consequently reducing genetic variation through bottle-neck effects. Compared to Mediterranean Europe, favourable environmental conditions in southern Africa (fig. 3: Schulze, 1994) is likely to reduce bottle-neck effects during winter, bringing about larger effective population sizes and a larger amount of within-population genetic variation.

\section{Gene flow between Africa and the Mediterranean}

The migration estimate between South Africa and Mediterranean Europe based on the AMOVA suggests reduced but measurable gene flow between the South African and Mediterranean populations (table 3). Transport routes connecting Africa and Europe through air and sea may increase the chances of inter-continental gene flow in G. bimaculatus, thereby maintaining the European genetic diversity in this species and providing founder populations. Although it is rare for these insects to fly long distances, swarms of G. bimaculatus were reported to land on ships passing the West Coast of Africa on route from the Canary Islands to southern Africa, the furthest ship being $933 \mathrm{~km}$ from land (Ragge, 1972). However, since these betweencontinent gene flow estimates are based on $F_{\mathrm{ST}}$, only they should be taken as tentative (Whitlock \& McCauley, 1999). In addition, more extensive sampling is required for a better understanding of cricket movements in Europe. Except for the Queenstown population, all the South African populations differed significantly from the Mediterranean populations (table 3).

\section{Gene flow within southern Africa}

The significant between-population genetic differentiation in South Africa was reflected by the large number of haplotypes only observed at single localities (26 of 31 haplotypes). This is similar to the results of Willett et al. (1997) who found that, for the COI-COII mtDNA gene in G. firmus and G. pennsylvanicus, all except one of the mtDNA haplotypes were restricted to single localities. The AMOVA, Bayesian MCMC estimates as well as the NCA revealed similar overall genetic divisions within South Africa (tables 2 and 3). Gene flow occurred within the northern region and within the southern region (tables 2 and 3). These two regions largely correspond to different climatic zones; northeastern South Africa is categorised as a summer rainfall area with a high annual rainfall, while southern and western South Africa are categorised by rain throughout the year and drier conditions except along the coast (Preston-Whyte \& Tyson, 1988; Schulze, 1994). This does not imply that these north-south differences are systematic. On the contrary, there are some unexpected exceptions indicated in tables 2 and 3. The large semi-arid to arid Karoo in central South Africa (Schulze, 1994) probably impedes natural gene flow between the northern and southern areas, due to isolated populations occurring around farm houses. Consequently, a lower level of migration occurred along the north-south gradient between the northern and southern regions, reflected by the top-level clades in fig. 2. One of the major inland road transport routes in South Africa follows a southwest to northeast direction (Business Monitor International, 2008) and incidentally could be a source of the intraspecific gene flow within South Africa. This could explain the unexpected high migration estimate between Pretoria and Paarl (tables 2 and 3). The historical explanation for genetic differentiation among South African populations of crickets (restricted gene flow superimposed on isolation by distance) appears to fit our observation well. However, this conclusion should be taken as tentative, taking into account recently-revealed weaknesses of nested clade analysis (Panchal \& Beaumont, 2007; Templeton, 2008).

\section{Usefulness of genetic information for interpreting between-population behavioural differences}

Ferreira \& Ferguson (2002) demonstrated significant differences between the calling song of G. bimaculatus from a number of South African populations, also reflected in significant between-population differences of the soundproducing structures on the wings of males from these populations. The same applies to crickets from Queenstown that differed significantly from other South African populations in most song traits, as well as in morphology (Ferreira, 2006). For instance, the calling song frequency at Queenstown was $6 \mathrm{kHz}$, almost $1 \mathrm{kHz}$ higher than in other southern African populations. This population was also genetically most distant from other southern African populations (table 2). Since the crickets come from localities ranging widely in rainfall, water availability and temperature, the question that arises is whether these differences are environmentally-induced or genetic in nature. The results from the molecular work reported here suggest that these 


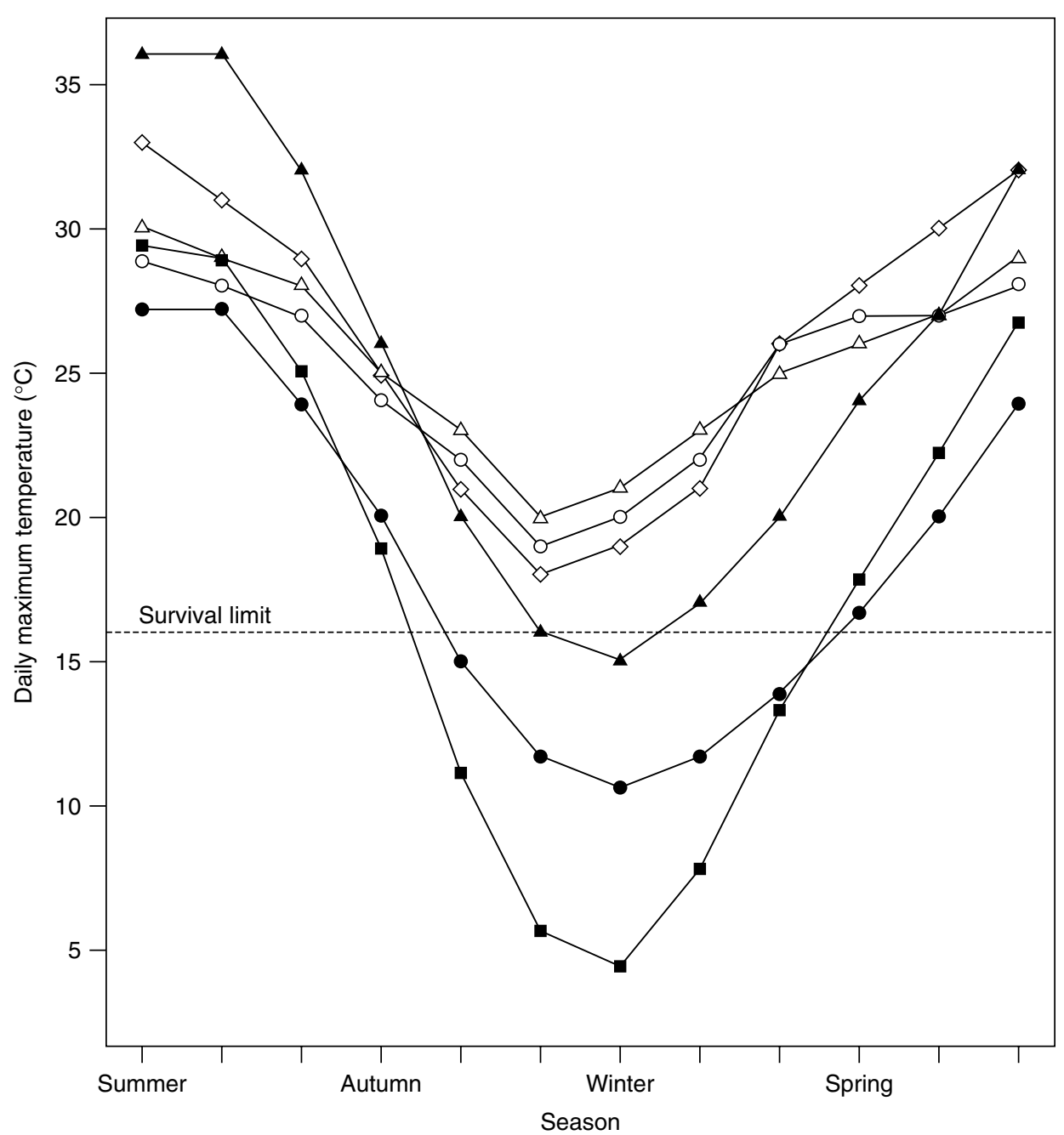

Fig. 3. Mean monthly daily maximum temperatures for six localities at, or close to, the sites where crickets were collected for this study. The horizontal line indicates the critical temperature below which cricket larvae do not survive and below which adult crickets do not show normal behaviour (see text). Data for Africa (months 1-12, Jan-Dec) and Europe (months 7-12, 1-6) were aligned in terms of season. Temperature data (means 1961-1990) were obtained from the World Meteorological Organisation as disseminated via the South

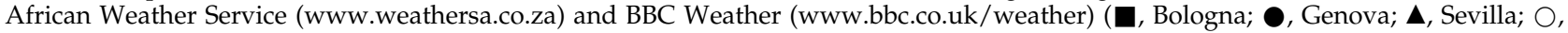
Pretoria; $\triangle$, Ladysmith; $\diamond$, Kimberley).

behavioural and morphological differences possibly have a genetic basis and that a closer investigation of the quantitative genetic characteristics of the songs of G. bimaculatus is justified.

Our results also provide insight into the interactions between European and African populations of crickets. Since our results strongly suggest longer-range dispersal as an important cause of genetic differentiation between populations, this dispersion is also likely to occur between Africa (both Mediterranean and further south) and Europe. The surprising conclusion from our work is that an insect with a wide international distribution across several continents shows clear geographical differences in genetic variation. The Mediterranean populations have surprisingly little genetic variation at the mitochondrial cyt $b$ locus, probably reflecting very small effective population sizes. Genetic variation in Europe is probably strongly affected by gene flow of genetic variants from environmentally stable parts of their geographic range, e.g. Africa. In this sense the Mediterranean area possibly comprises marginal habitat for the Mediterranean cricket.

This study also highlights the disjointed and nonsystematic pattern of gene flow that exists even in insects that are cosmopolitan in geographic range, also observed in other cricket species. These disjointed gene flow patterns are likely part of the explanation for morphological and behavioural differences found in different populations of these insects.

\section{Acknowledgements}

We would like to thank the farmers from Dullstroom, Dundee, Makhado, Paarl and Queenstown for allowing us to collect crickets on their properties. A.D. Slagor-Bastos, 
W. Delport, G.P. Malherbe and J. Roy are thanked for their laboratory and statistical assistance. L. Verburgt as well as $X$. Cerda and other staff of the CSIC Estación Biológica de Doñana, Spain are thanked for enabling us to collect material in Spain. The Deutche Forchungsgemeinschaft (DFG) funded the collection of material from Europe. The National Research Foundation (NRF South Africa) and University of Pretoria supported this work.

\section{References}

Arctander, P. (1995) Comparison of a mitochondrial gene and a corresponding nuclear pseudogene. Proceedings of the Royal Society of London B 262, 13-19.

Beerli, P. (2004) Comparison of Bayesian and maximumlikelihood inference of population genetic parameters. Bioinformatics 22, 341-345.

Bensasson, D., Zhang, D.-X. \& Hewitt, G.M. (2000) Frequent assimilation of mitochondrial DNA by grasshopper nuclear genomes. Molecular Biology and Evolution 17, 406-415.

Bretman, A.J., Wedell, N. \& Tregenza, T. (2004) Molecular evidence of post-copulatory inbreeding avoidance in the field cricket Gryllus bimaculatus. Proceedings of the Royal Society of London. Series B: Biological Sciences 271, 159-164.

Broughton, R.E. \& Harrison, R.G. (2003) Nuclear gene genealogies reveal historical, demographic and selective factors associated with speciation in field crickets. Genetics 163, 1389-1401.

Business Monitor International (2008) The South Africa Freight Transport Report 2008. Business Monitor Inernational. London, Blackfriars.

Castelloe, J. \& Templeton, A.R. (1994) Root probabilities for intraspecific gene trees under neutral coalescent theory. Molecular Phylogenetics and Evolution 3, 102-113.

Clement, M. \& Posada, D. \& Crandall, K.A. (2000) TCS: a computer program to estimate gene genealogies. Molecular Ecology 9, 1657-1660.

Donnelly, P. \& Tavarè, S. (1986) The ages of alleles and a coalescent. Advances in Applied Probability 18, 1-19.

Excoffier, L., Smouse, P.E. \& Quattro, J.M. (1992) Analysis of molecular variance inferred from metric distances among DNA haplotypes: application to human mitochondrial DNA restriction data. Genetics 131, 479-491.

Ferreira, M. (2006) Evolutionary implications of variation in the calling song of the cricket Gryllus bimaculatus De Geer (Orthoptera: Gryllidae). MSc thesis, University of Pretoria. Pretoria, South Africa.

Ferreira, M. \& Ferguson, J.W.H. (2002) Geographic variation in the calling song of the field cricket Gryllus bimaculatus (Orthoptera: Gryllidae) and its relevance to mate recognition and mate choice. Journal of Zoology, London 257, $163-170$.

Harley, E.H. (2000) Dapsa: A program for DNA and protein sequence analysis, version 4.9. Department of Chemical Pathology, University of Cape Town, South Africa.

Harrison, R.G. \& Bogdanowicz, S.M. (1995) Mitochondrial DNA phylogeny of North American field crickets: perspectives on the evolution of life cycles, songs, and habitat associations. Journal of evolutionary Biology 8, 209-232.

Ji, Y.-J., Zhang, D.-X. \& He, L.-J. (2003) Evolutionary conservation and versatility of a new set of primers for amplifying the ribosomal internal transcribed spacer regions in insects and other invertebrates. Molecular Ecology Notes 3, 581-585.
Lansman, R.A., Shade, R.O., Shapira, J.F. \& Avise, J.C. (1981) The use of restriction endonucleases to measure mitochondrial DNA sequence relatedness in natural populations. III. Techniques and potential applications. Journal of Molecular Evolution 17, 214-226.

Liedloff, A. (1999) Mantel nonparametric test calculator for Windows, version 2.0. School of Natural Resource Sciences, Queensland University of Technology, Brisbane, Australia.

Mantel, N. (1967) The detection of disease clustering and a generalised regression approach. Cancer Research 27, 209-220.

McCarthy, C. (1996) Chromas, version 1.45. School of Biomolecular and Biomedical Science, Griffith University, Southport, Queensland, Australia.

Panchal, M. \& Beaumont, M.A. (2007) The automation and evaluation of nested clade phylogeographic analysis. Evolution 61, 1466-1480.

Posada, D. \& Crandall, K.A. (1998) Modeltest: testing the model of DNA substitution. Bioinformatics 14, 817-818.

Posada, D., Crandall, K.A. \& Templeton, A.R. (2000) GeoDis: a program for the cladistic nested analysis of the geographical distribution of genetic haplotypes. Molecular Ecology 9, 487-488.

Preston-Whyte, R.A. \& Tyson, P.D. (1988) The Atmosphere and Meather of Southern Africa. 374 pp. Cape Town, South Africa, Oxford University Press.

Ragge, D.R. (1972) An unusual case of mass migration by flight in Gryllus bimaculatus DeGeer (Orthoptera Gryllidae). Bulletin de l'Instution fond d'Afrique noire A 34, 869-878.

Roff, D.A. \& Bentzen, P. (1989) The statistical analysis of mitochondrial DNA polymorphisms: $\chi^{2}$ and the problem of small samples. Molecular Biology and Evolution 6, 539-545.

Ryan, M.J., Rand, A.S. \& Weigt, L.A. (1996) Allozyme and advertisement call variation in the túngara frog, Physalaemus pustulosus. Evolution 50, 2435-2447.

Schneider, S., Roessli, D. \& Excoffier, L. (2000) Arlequin, version 2.000. A software for population genetics data analysis. Genetics and Biometry Laboratory, University of Geneva. Geneva, Switzerland.

Schulze, B.R. (1994) Climate of South Africa. Part 8: General survey. South African Weather Service, Department of Environment affairs, Pretoria, South Africa.

Tamura, K. \& Nei, M. (1993) Estimation of the number of nucleotide substitutions in the control region of mitochondrial DNA in humans and chimpanzees. Molecular Biology and Evolution 10, 512-526.

Templeton, A.R. (2004) Statistical phylogeography: methods of evaluating and minimizing inference errors. Molecular Ecology 13, 789-809.

Templeton, A.R. (2008) Nested clade analysis: an extensively validated method for strong phylogeographic inference. Molecular Ecology 17, 1877-1880.

Templeton, A.R. \& Sing, C.F. (1993) A cladistic analysis of phenotypic associations with haplotypes inferred from restriction endonuclease mapping. IV. Nested analyses with cladogram uncertainty and recombination. Genetics 134, 659-669.

Templeton, A.R., Crandall, K.A. \& Sing, C.F. (1992) A cladistic analysis of phenotypic associations with haplotypes inferred from restriction endonuclease mapping and DNA sequence data. III. Cladogram estimation. Genetics 132, 619-633.

van Wyk, W.J. \& Ferguson, J.W.H. (1995) Communicatory constraints on field crickets Gryllus bimaculatus calling at 
low ambient temperatures. Journal of Insect Physiology 41, 837-841.

Walsh, P.S., Metzger, D.A. \& Higuchi, R. (1991) Chelex ${ }^{\circledR} 100$ as a medium for simple extraction of DNA for PCR-based typing from forensic material. BioTechniques 10, 506-513.

Whitlock, M.C. \& McCauley, D.E. (1999) Indirect measures of gene flow and migration: $F_{\mathrm{ST}} \neq 1 /(4 \mathrm{Nm}+1)$. Heredity 82 , 117-125.
Willett, C.S., Ford, M.J. \& Harrison, R.G. (1997) Inferences about the origin of a field cricket hybrid zone from a mitochondrial DNA phylogeny. Heredity 79, 484494.

Zhang, D.-X. \& Hewitt, G.M. (1996) Highly conserved nuclear copies of the mitochondrial control region in the desert locust Schistocerca gregaria: some implications for population studies. Molecular Ecology 5, 295-300. 